\title{
The Effect of Using Print Media on Children's L2 Literacy Development: A Longitudinal Study
}

\author{
Mansoor Tavakoli \\ Department of English Language and Literature, Faculty of Foreign Languages, University of Isfahan, Isfahan, Iran \\ Saeedeh Esmae'li (Corresponding author) \\ Depart ment of English Language and Literature, Faculty of Foreign Languages, University of Isfahan, Isfahan, Iran
}

\begin{abstract}
This paper tries to examine the effect of using print media in the classroom on the children's $\mathbf{L 2}$ literacy development in an EFL context. Since reading is regarded as a chief goal, in many second/foreign language teaching situations, it receives a special focus. Media as a tool for language learning/teaching, can help both instructed and non-instructed learners to overcome the difficult task of language learning. In order to determine the effects of print media usage on the development of children's foreign language reading abilities, 30 children aged between 7-8 familiar to English alphabet were selected. Based on DIBELS performance, participants were homogenized and assigned as low group. According to National Reading Panel, story books, magazines and newspapers were used to teach five areas of reading proficiency, i.e. phonemic awareness, phonics, fluency, vocabulary and text comprehension. After one year of instruction, based on DIBELS performance, participants were assigned to medium and high groups; implying the effect of direct instruction and print media usage in classrooms for developing foreign language reading abilities.
\end{abstract}

Index Terms - L2 literacy development, reading ability, print media use, childhood education, DIBELS (dynamic indicators of basic earty literacy skills)

\section{INTRODUCTION}

In most of the second or foreign language teaching situations, reading receives a particular attention. Richards and Renandya (2002) remark a nu mber of reasons for this. First, reading is considered as one of the most important goals of foreign language learners; because learners want to be able to read for different reasons such as reading for information and pleasure, reading for study purposes and reading for their career. In other words, the ability to read in a foreign language is all that students want to acquire in most EFL contexts. Second, good reading texts provide opportunities to introduce new topics for discussion as well as to studying language (e.g., vocabulary, grammar, and idio ms), they also provide good models for writing. Therefore, extensive exposure to comprehensible texts can enhance the process of language learning. Reading, then, is a skill which is highly valued by EFL learners and teachers (Richards \& Renandya, 2002).

In recent years, specially, there has been increased focus on teaching of reading and other literacy skills to children, both in North America and abroad. According to Ediger (cited in Celce-Murcia, 2001), the recognition that reading is the most important skill for L2 learners in academic contexts (Grabe, 1991) can be one reason for this. An increase in the numbers of children learning English as a second/ foreign language can be the second reason. The belief that basic literacy instruction should be a fundamental component of public education can be considered as the third reason. Finally, the growing numbers of countries which are moving toward making English language instruction mandatory from a younger age is the fourth reason. In Korea and Taiwan, for instance, English is now a required subject, beginning in the third grade. According to Celce-Murcia (2001), because of the portability of books and other reading materials, reading is gradually being recognized as a valuable source of language input, particularly for students in learning environments (as in Iran) in which fluent speakers of English are generally not available to provide other kinds of language input.

As mentioned, reading can be considered as one of the most important skills for the EFL learners. Additionally, children's future success in reading can be predicted by the extent of the development of their literacy concept, knowledge and skills in early childhood (Adams, 1990; Donaldson, 1978; Snow, Burns, \& Griffin, 1998; Whitehurst \& Lonigan, 1998). On one hand, early reading is dependent on understanding of the internal structure of words, and on the other hand, it can be promoted by explicit instruction in phonological awareness. However, early reading instruction, especially explicit instruction in letter-sound correspondence strengthens phonological awareness, and in particular leads to the more phonemic awareness (Snow et al., 1998). As cited in Hinkle (2006), researchers such as Paran (1996), Birch (2002), and Koda (2005) consider the top-down reading skills as additive or compensatory while fluent bottom-up processing is achieved. In other words, at the first stages of learning the bottom-up processing is considered to be more important than top-down processing. Since the existing learning-teaching formula in Iran, especially for child ren, does not focus on sub-skills and components of reading, the children struggle to read and they have serious problems in 
distinguishing English alphabets when reading. Thus, the present research aimed at investigating the effect of using print media as a tool in classroom to develop children's literacy and reading sub-skills. The review of the related literature, therefore, is done in the next section.

\section{THEORETICAL BACKGROUND}

As was mentioned, the purpose of the present study was to investigate the effect of using print media on literacy development. Theoretical background, therefore, will be divided into two parts, i.e. the variables of the study: 1) L2 literacy development, and 2) use of media in classroom.

\section{A. L2 Literacy Development}

Alderson (2000) defines reading as "...an enjoyable, intense, private activity, from which much pleasure can be derived, and in which one can become, totally absorbed (p. 28)." However, reading means different things to different people. For some it is understanding written texts, while for others it is a chance to practice speaking skill and to teach pronunciation. In fact, reading has a purpose. It is an activity that we do every day, i.e., it is an essential component of our daily lives, taken for granted and generally assumed that everyone can do.

Since the 1980s, research on reading, both in first and second language contexts has been developed (Grabe as cited in Richards \& Renandya, 2002). Although the development in first language contexts has led to improvements in reading instruction, the corresponding research in L2 contexts has not made much headway. In fact, different theories which exist to explain what is involved when we read, and much of what we know about reading and literacy come from research on first language learners (Richards \& Renandya, 2002).

A critical element in a child's success in school and life is learning to read early and well (Lane, Pullen, Hudson, \& Konold, 2009). The level to which the child progresses in reading can be used to predict the competent function of a child in school and her/his active contribution in our literate society. In fact, reading achievement is closely related to social and economic achievement (Baydar, Brooks-Gunn, \& Furstenberg, 1993; Blaunstein \& Lyon, 2006). Although throughout the life span reading sub-skills abilities continue to develop, the most important period for literacy development is the early childhood years. Rich literate environments develop children's understanding of the concepts underlying reading (Adams, 1990; Dickinson \& Tabors, 2001). Recent research in the realm of reading has shown that children who start off poorly in reading remain poor readers throughout their schooling and beyond (Adams, 1990; Francis, Shaywitz, Stuebing, Shaywitz, \& Fletcher, 1996; Juel, 1988; Stanovich, 1986; Torgesen \& Burgess, 1998). This phenomenon has been described by Stanovich (1986) as the Matthew Effect - the rich get richer and the poor get poorer. If we want to make a positive change in the lives of children, we must provide appropriate supports during the early childhood years in order to minimize or even prevent the development of reading difficulties.

Eskey (1988) in his overview of reading research, examines "a strongly top-down bias" (p. 95) in L2 reading pedagogy and neglect of learners' weak linguistic processing skills. Eskey's analysis shows that L2 readers are basically distinct from those who read in their L1s and that essential "knowledge of the language of the text" (p. 96) is required before learners can successfully process the L2 reading schema. In other words, he emphasizes the bottom-up skills. The bottom-up processing of reading includes a vast array of distinct cognitive sub-skills, i.e., word recognition, spelling and phonological processing, morpho-syntactic parsing, and lexical recognition and access (Eskey, 2005). The reader should gather visual information from the written text (e.g., letters and words), identify the meanings of words, and then try to process the structure and the meaning of larger syntactic units, such as phrases or sentences. Several studies, like those by Koda (1999), Chikamatsu (1996), and Shimron and Savon (1994), have indicated that visual processing of words and letters in written text represents a cognitively complex task.

National Reading Panel, after exhaustive study summarizing research studies on reading since 1966, published its findings in 2000. Its first report was called Preventing Reading Difficulties in Young Children. The National Reading Panel summarizes strategies to improve student reading proficiency. The research results were a composite of more than 100,000 studies. National Reading Panel recommends five elements for developing reading ability. Each activity relies on the previous one. Each accomplishment becomes a build ing block for the next. Following the guidelines of National Reading Panel, the five areas of reading proficiency critical for children to learn to read are 1) phonological awareness, 2) phonics, 3) fluency, 4) vocabulary, and 5) text comprehension. First a child should learn letter names and sounds, then s/he should develop sight words, later s/he will become more fluent and will be able to move more quickly through text, therefore s/he will accomplish more difficult reading tasks such as learning new vocabulary and understanding what is read. So through learning systematically, the child 'learns how to read'. The National Reading Panel, however, suggests that teachers who work with English language learners must be aware that the sounds of English differ from other phonetic languages and that these differences could bring about difficulty for students in learning English word structures. Additionally, vocabulary proficiencies can affect comprehension. However, recent ELL research suggests that regardless of primary language, all children must learn these reading sub-skills and that English-driven reading instruction with these sub-skills is linked to reading success (Baker \& Gersten, 1997; Garcia, 2000; Gersten \& Geva, 2003). On the same way and according to Committee on the Prevention of Reading Difficulties in Young Children, in order to begin reading instruction, there should be an emphasis on 1) using reading to obtain meaning from print, 2) the phonological and morphological structure of words, 3) the orthographic system, 4) regular spelling-sound relationships, 
and 5) frequent opportunities to read and write (Snow et al., 1998; Foorman \& Torgesen, 2001). Children learn ing to read and write Eng lish for the first time, therefore, may need assistance with developing an understanding of notions such as the following (Clay, 1993; Justice \& Ezell, 2001):

1. The print tells the story.

2. Pictures go with text.

3. We read from left to right, front to back, top to bottom.

4. Words are written separately from each other and the white spaces between groups of letters represent a break between spoken words or word boundaries.

5. Punctuation marks separate notions or ideas from each other.

6. Quotation marks mean that someone is speaking.

7. Written language has different rules and conventions from oral language.

8. When one page of text is read, the story continues on the following page.

\section{B. Use of Media in Classroom}

The children of the 21 st century live in a world rich with technology. They are surrounded by the Internet, Web sites, emails, chat rooms, cellphones, discussion boards, electronic toys and learning games, and so on (Siraj-Blatchford \& Whitebread, 2003). So they are called "Digital Children" (Edyburn, 2002). When families use technology, their young children will develop and acquire skills in language as well as literacy through exposure to technology in the home (Jewitt, 2006). Computers by providing multimodal experiences such as images, color, visual layout, sound, and movement, assist children to develop understandings of special kind of communication events within language based social contexts (Jewitt, 2006). Technology and media provide tools that can be used as facilitators to help young children construct their knowledge of the world (Jonassen \& Howland, 2003).

Media as a tool for language learning/teaching, can assist both instructed and non-instructed learners to overcome the task of language learning. Just as children learning a first or second language grasp the meaning of words from objects that surround them, non-native speakers (both inside and outside the classroom) make use of the here and now or objects in the immediate environment to process incoming speech (Brinton as cited in Celce-Murcia, 2001). It seems that language teachers agree that media can and do improve language teaching, and therefore, we can find a range of media in the daily practice of language teaching - from non-mechanical aids such as household objects, flashcards, and magazine pictures all the way up to sophisticated mechanical aids such as video cameras and computer - assisting teachers in their job, bringing the outside world into the realm of classroom, and making the difficult task of language learning more meaningful and exciting task.

'It is germane here to differentiate between 'large $\mathrm{M}$ media' and 's mall m media'. Media means many different things to different people. 'The most immed iate connotation of the term 'med ia', at least as related to language teaching, is that of the 'large M media' - of technological innovations in language teaching, of mechanical paraphernalia, and of glossy, polished audiovisual aids - with all the media an xiety that these can conjure up in teachers. However, there is little evidence that such glossy audiovisual aids are more effective than teacher-made, non-mechanical aids (e.g., paper plate hand puppets, butcher paper verb charts, and the like) or props from daily life (e.g., cereal boxes, campaign buttons, travel pamphlets, bumper stickers) that have been adapted for classroom teaching purposes' (Brinton as cited in Celce-Murcia, 2001, p. 460). It would be better to suggest that all these aids, mechanical and non-mechanical, glossy and non-glossy, commercially available and teacher-made, should be part of our defin ition of language teaching media.

In Brinton's words (as cited in Celce-Murcia) print media (such media will be described in the Method section) help us to motivate students by bringing a slice of real life into the classroom and by presenting language in its more complete communicative context. Media can also provide a density of information and richness of cultural input not otherwise possible in the classroom, they can help students process information and free the teacher from excessive explanation, and they can provide contextualization and a solid point of departure for class room activities. The following statements summarize the rational for using media in the language classroom (Brinton as cited in CelceMurcia, 2001, pp. 461-462):

1. Given the role media play in the world outside the classroom, students expect to find media inside the classroom as well. Media thus serve as an important motivator in the language teaching process.

2. Media materials can lend authenticity to the classroom situation, reinforcing for students the direct relation between the language classroom and the outside world.

3. Since the learning styles of students differ (Oxford, 1990; Reid, 1987; Skehan, 1980; Wenden \& Rubin, 1987), media provide us with a way of addressing the needs of both visual and auditory learners.

4. The role that input plays in language learning is virtually uncontested (Krashen, 1987). By bringing med ia into the classroom, teachers can expose their students to multiple input sources. Thus, while decreasing the risk of the students' becoming dependent on their teacher's dialect or idiolect, they can also enrich their language learning experiences.

5. With references to schema theory (Schank \& Abelson, 1977), which proposes that we approach new information by scanning our memory banks for related knowledge, media can help students call up existing schemata and therefore maximize their use of prior background knowledge in the language learning process. 
6. Finally, research suggests that media provide teachers with a means of presenting material in a time-efficient and compact manner, and of stimulating students' senses, thereby helping them to process information more readily (Mollica, 1997).

\section{PURPOSE AND RESEARCH QUEST IONS}

Since reading achievement in early childhood is highly predictive of later reading success or failure (Juel, 1988; Stanovich, 1986; Torgesen, 2004), the importance of early intervention is quite clear. The fact that early, intensive reading instruction could alleviate early reading failures and narrow the achievement gap warrants further attention. Therefore, to enhance the potential for children in the primacy grades to succeed in early reading instruction, the current research examined the use of print media in classroom to develop the children's L2 literacy. The focus of the study was mostly on sub-skills such as phonemic awareness, fluency, and text comprehension. Phonemic awareness is taken to refer to a pre-reading skill; it is the ability to notice, think about and work with the individual sounds (phonemes) in spoken words. Phonemic a wareness is, therefore, the ability to manipulate language at the phonemic level, that is, to "reflect on the component sounds of spoken words, rather than on their meanings" (Goswami, 2000, p. 251). Before children learn to read print, they must become aware of how sounds work in words. This includes identifying beginning, medial and ending sounds, hearing rhythm and rhy mes, and understanding nuances in spoken words (National Reading Panel, 2000). Although phonemic processing ability appears to remain relatively stable over time (Wagner, Torgesen, Rashotte, Hecht, Barke, \& Burgess, 1997), research has shown that phonemic awareness skills, as mentioned, can be taught and that gains in phonemic awareness are as sociated with corresponding gains in reading achievement (Lie, 1991; Torgesen, Morgan, \& Davis, 1992; Vellutino \& Scanlon, 1987). Phonemic awareness is operationally defined as the performance of the participants on DIBELS (Dynamic Ind icators of Basic Early Literacy Skills) Phoneme Seg mentation Test, edited by Good and Kaminski (2007). Fluency is taken to refer to the ability to read text accurately and quickly. This occurs when readers read silently and recognize words automatically. Fluent readers read effortlessly; fluency is the bridge to reading comprehension (National Reading Panel, 2000). Fluency is operationally defined as the performance of the participants on DIBELS (Dynamic Indicators of Basic Early Literacy Skills) Oral Reading Fluency Test, edited by Good and Kaminski (2007). Text comprehension is taken to refer to understanding what is read. To truly comprehend text, reading must be purposeful and active (National Reading Panel, 2000). Text comprehension is operationally defined as the performance of the participants on retell part of DIBELS (Dynamic Indicators of Basic Early Literacy Skills) Oral Reading Fluency Test, edited by Good and Kaminski (2007).

According to what was discussed above regarding the problem and purpose of the study, the present research addresses the following research questions:

1. What is the effect of print med ia use on developing children's phonemic awareness?

2. What is the effect of print med ia use on development of child ren's fluency?

3. What is the effect of print media use on developing children's text comprehension?

\section{METHOD}

\section{A. Research Design}

Since we had a control group and an experimental group, the design of the study was experimental. Using tables of random numbers, participants were selected randomly and each group was given a pre-test and a posttest. For each group a phoneme segmentation test was given as a pre-test, and a phoneme segmentation test and an oral reading fluency test were used as posttests.

\section{B. Participants}

The participants of this study were 40 female children within the age range of 7-8 familiar to English alphabets. The participants had studied English at one school in Esfahan, Iran. They were selected randomly from two classes of the mentioned school. From the 40 students 30 students qualified for inclusion. These students met the criteria of a) having parental permission, and b) likely to remain at the school during the course of the study. Using tables of random numbers, these 30 children were divided into two equal groups, i.e. experimental and control groups.

\section{Materials}

The materials used were as follows:

\section{DIB ELS (Dynamic Indicators of Basic Early Literacy Skills) Phoneme Segmentation Test}

This test consists of 20 progress monitoring sub-tests. Each sub-test consists of 24 words, presented in increasing order of difficulty. The first progress monitoring sub-test was used as a pre-test and in order to homogenize the participants. The Cronbach alpha coefficient of this test in the current study was .84 . The other 19 progress monitoring sub-tests were used during the course of study.

\section{DIB ELS (Dynamic Indicators of Basic Early Literacy Skills) Oral Reading Fluency Test}

This is a graded reading test which has 6 stages from the first grade to the sixth grade and each stage consists of 20 sub-tests. At the end of each sub-test, the students should retell the studied passages in their own words in order to test 
the students' comprehension of the text. The first, second, and third stages were used in this study. However, because of the long sub-tests, sub-tests numbers 1, 5, 10, 15, and 20 of each stage had been used. The Cronbach alpha coefficient (re liability) of these tes ts in the current study were $.83, .85, .85, .86$, and .86 respectively.

\section{Sails Book Series}

This book series consist of 35 graded books fro mearly 1 to early 4 . Each book includes 3 titles: a) thin king critically, b) exploring language, and c) processing information. Under the title thinking critically there are some sample questions such as "When would you use a map?" and "Look at pages 12 and 13. How do you think Molly and Henri feel about Miss Grimble?" which should be used as pre-reading questions and activities. Under the title exploring language there are the following sub-titles with some guidelines for the teacher to help the students to explore their language: a) terminology: speaking about the title, cover, author, etc., b) vocabulary: introducing interest words, high -frequency words, positional words, etc., c) print conventions: introducing punctuation such as full stop, commas, etc., d) phonological patterns: working on the most repeated phonemes in each story, and e) visual information: using pictures in each story to gain information. And finally, under processing information title, there are some guidelines and questions such as "Retell the story." and "Get the children to draw and label a map showing how to go from one place to another." for processing information including oral, written and visual language. The last two titles, i.e. exploring language and processing information should be used as post-reading activities.

\section{Teenager Mag azine}

This magazine is designed for teenagers; however, at the end of it there is part named "Ladder" designed for the kids. This part includes a) kids' story, b) kids' crossword, c) kids' poem, d) kids' fun and e) knowledge.

\section{News paper}

The instructor used different books, magazines and websites in order to produce newspapers for kids. The mentioned news papers were colorful and attractive for children. They include a) charts, graphs, and diagrams, b) maps, c) tables , d) pictures, and e) cartoons and comic strips. Later the participants were asked to make their own newspapers for the class and share the information with each other.

\section{Procedure}

The first progress monitoring sub-test of the DIBELS phoneme segmentation test was used as a pre-test for both groups and in order to investigate the level of the children. All the participants were at the same level and we re assigned as low level. A though they were familiar to the English alphabets, they were not able to diag nose the alphabets in the list of words and they could not pronounce them correctly. In fact, their phonemic awareness was considered as very low.

The control group participated in 30 minutes classes once a week. Although they were familiar to English alph abets, based on the school's rule Let's Go Starter was used to teach English. The control group received traditional instructions, i.e. each session they were taught 3-4 vocabularies start with one of the English alphabet without focusing on phonemes. First the alphabet was introduced and after some repetitions the vocabularies we re introduced. There was no use of rhyming or comparing the phonemes.

On the other hand, the experimental group participated in whole-class activities for 45 minutes, three times per week. Sails book series were used to teach phonemes, phonics and vocabulary through stories and direct instruction to the experimental group. During teaching the mentioned parts, the other 19 progress monitoring sub-tests of the DIBELS phoneme segmentation test were used to investigate the progress of the participants. However, when the students were familiar with some of the vocabularies, the kids' cross words and kids' fun of the Teenager magazine were used.

After 3 months of instruction, the children were able to read the stories of the Sails book series and had developed their phonemic awareness and vocabularies. At this time stories and poems of the Ladder part of the Teenager magazine were used in order to familiar the participant with more complicated stories and vocabularies. At the end of each story in the magazine, there is a quiz used in order to check the participants' text comprehension.

After 3 months of using magazine, the children became conversant with the mentioned stories and were able to read them; thus, the instructor used the teacher-made newspapers. Gradually the children learned to read tables, graphs, maps, etc. At this time which was the middle of the year of instruction, the first grade of the DIBELS oral reading fluency test was used and as was expected all the students were able to read and pass this level, i.e. first grade.

After one month of working on teacher-made newspapers, the instructor wanted the participants to make their own newspapers and share them with their friends. At this time, however, the students were able to produce cartons and comic strips and to read them. The instructor and students worked on students -made newspapers for 2 months.

At the end of the educational year which lasted nine months, the second grade of DIBELS oral reading fluency test was used, surprisingly all the students had passed it and were assigned as high group. To investigate the exact level of the participants' reading ability, the thirds grade of the aforementioned test was used. Based on the children's performance on this last test, they were assigned as high and medium groups. To ensure that the results were due to the instruction not growing of the children, the other 15 children of the control group who had not received the direct instructions mentioned before, but had studies English as a foreign language were tested by the first sub-test of the DIBELS phoneme segmentation test and the first grade of the DIBELS oral reading fluency test. They were not able to read the reading fluency test and their performance on phonemic segmentation test was very low. 


\section{RESULTS}

The first sub-test of DIBELS phoneme segmentation test, as mentioned before, was used as pre-test. The mean score of the subjects' performance on this test is 2.26 which is very low and implies the low phonemic awareness of the participants. During teaching phonemes and phonetics, the other 19 sub-tests of DIBELS phoneme segmentation test were used to as sess phonemic a wareness and progress of the experimental group. The mean scores of sub-tests numbers $5,10,15$, and 20 are shown in Table 1.

TABLE 1.

EXPERIMENTAL GROUP'S PHONEMIC AWARENESS RESULTS

\begin{tabular}{|l|l|l|l|l|l|}
\hline DIBELS PST & Test 1 & Test 5 & Test 10 & Test 15 & Test 20 \\
\hline Mean Score & 2.26 & 36.53 & 46.93 & 56.93 & 67.77 \\
\hline
\end{tabular}

Table 2 shows the mean score of subjects' performance on sub-tests numbers 5, 10, 15, and 20 of each grade of DIBELS o ral reading fluency test. Based on DIBELS' instruction and guidance, the subjects had passed grades 1 and 2 and they would be assigned as high level. The results of the third grade, however, are a little different. Based on DIBELS' instruction, the subjects were assigned to high level with mean score 239 and to medium level with mean score 223 .

TABLE 2.

EXPERIMENTAL GROUP'SORAL READING FLUENCY RESULTS

\begin{tabular}{|l|l|l|l|l|}
\hline DIBELS ORFT & Grade 1 & Grade 2 & Grade 3 & High \\
\hline Mean Score & & & Medium \\
\hline
\end{tabular}

ORFT = Oral Reading Fluency Test

Table 3 shows the results of the retell part of DIBELS oral reading fluency tests grades 1,2 , and 3 . The maximum mean score for each of the a forementioned tests is 94 . It can be understood that the students' comprehension is high and they would be assigned as high level. However, subjects' performance on the third grade of aforementioned test was different. The students are assigned as high level with mean score 86.75 and as medium level with mean score 84.42 . Since the students were not able to read at the beginning of the study, their comprehension could not have been measured. The decrease in the subjects' text comprehension could be explained with the difficulty of the tests for the students. However, it should be reminded that at the end of the study and at the time of this test the participants were within the age range of 8-9 and as a result reading and comprehending the third level with mean score 85.66 could be considered a great progress for the subjects.

TABLE 3.

EXPERIMENTAL GROUP'S RETELL RESULTS

\begin{tabular}{|l|l|l|l|l|}
\hline DIBELS Retell & Grade 1 & Grade 2 & Grade 3 & High \\
\cline { 3 - 6 } & & & Medium \\
\hline Mean Score & 89.6 & 87.73 & 86.75 & 82.42 \\
\hline
\end{tabular}

As was mentioned, the first sub-test of DIBELS phoneme segmentation test and the first grade of DIBELS oral reading fluency test were used to measure phonemic awareness and reading ability of the other 15 students, i.e. control group at the end of study. Table 4 shows the results of these two tests. Based on their performance on DIBELS phoneme segmentation test, they are assigned as low level. The mean score of the oral reading fluency test is 37.77 showing that they could not pass this level of reading. As they were not able to read the reading sub-tests, they could not retell the passages showing their lack of comprehension.

TABLE 4.

CONTROL GROUP'S PHONEMIC AW ARENESS AND ORAL READING FLUENCY RESULTS

\begin{tabular}{|l|l|l|}
\hline DIBELS TEST & PST/Sub-test 1 & ORFT/Grade 1 \\
\hline Mean Scores & 10.45 & 37.77 \\
\hline
\end{tabular}

In order to compare the phonemic a wareness scores of two groups, an independent samples t-test was conducted. The results showed that the scores obtained on DIBELS phoneme segmentation test are significantly different across the two groups ( $\mathrm{t}(30)=99.95, \mathrm{p}<.05)$ (see Table 5). The magnitude of the differences in the mean was very large (eta squared $=.99)$. 
TABLE 5.

INDEPENDENT SAMPLES T-TEST BETWEEN EXPERIMENTAL AND CONTROL GROUPS REGARDING PHONEMIC AWARENESS

\begin{tabular}{|c|c|c|c|c|c|c|c|c|c|c|}
\hline & & \multicolumn{2}{|c|}{$\begin{array}{l}\text { Le vene's Test for Equality } \\
\text { of Variances }\end{array}$} & \multicolumn{7}{|c|}{ t-test for Equality of Means } \\
\hline & & \multirow[t]{2}{*}{$\mathbf{F}$} & \multirow[t]{2}{*}{ Sig. } & \multirow[t]{2}{*}{$\mathbf{t}$} & \multirow[t]{2}{*}{ df } & \multirow[t]{2}{*}{$\begin{array}{l}\text { Sig. (2- } \\
\text { tailed) }\end{array}$} & \multirow[t]{2}{*}{$\begin{array}{l}\text { Mean } \\
\text { Difference }\end{array}$} & \multirow[t]{2}{*}{$\begin{array}{l}\text { Std. Error } \\
\text { Difference }\end{array}$} & \multicolumn{2}{|c|}{$\begin{array}{l}95 \% \text { Confidence } \\
\text { of the Diffe rence }\end{array}$} \\
\hline & & & & & & & & & Lower & Upper \\
\hline PST20 & $\begin{array}{l}\text { Equal } \\
\text { V } \\
\text { assumed } \\
\text { Equal } \\
\text { V not } \\
\text { Assumed }\end{array}$ & 5.148 & .031 & 99.95 & 22.59 & .000 & 57.267 & .573 & 56.09 & 58.44 \\
\hline
\end{tabular}

PST = Phoneme Segmentation Test, V = Variance

Another independent samples t-test was conducted to compare the fluency scores of two groups. The results showed that the obtained scores on DIBELS oral reading fluency test are significantly different across the two groups $(\mathrm{t}(30)=$ $87.73, \mathrm{p}<.05$ ) (see Table 6). The magnitude of the differences in the means was very large (eta squared $=.99$ ).

TABLE 6.

INDEPENDENT SAMPLES T-TEST BETWEEN EXPERIMENTAL AND CONTROL GROUPS REGARDING READING FLUENCY

\begin{tabular}{|c|c|c|c|c|c|c|c|c|c|}
\hline & \multicolumn{2}{|c|}{$\begin{array}{l}\text { Le vene's Test for Equality } \\
\text { of Variances }\end{array}$} & \multicolumn{7}{|c|}{ t-test for Equality of Means } \\
\hline & \multirow[t]{2}{*}{$\mathbf{F}$} & \multirow[t]{2}{*}{ Sig. } & \multirow[t]{2}{*}{$\mathbf{t}$} & \multirow[t]{2}{*}{ df } & \multirow[t]{2}{*}{$\begin{array}{l}\text { Sig. (2- } \\
\text { tailed) }\end{array}$} & \multirow[t]{2}{*}{$\begin{array}{l}\text { Mean } \\
\text { Difference }\end{array}$} & \multirow[t]{2}{*}{$\begin{array}{l}\text { Std. Error } \\
\text { Difference }\end{array}$} & \multicolumn{2}{|c|}{$\begin{array}{l}95 \% \text { Confidence } \\
\text { of the Difference }\end{array}$} \\
\hline & & & & & & & & Lower & Upper \\
\hline $\begin{array}{ll}\text { ORFT,G3 } & \text { Equal } \\
& \text { V } \\
& \text { assumed } \\
\text { Equal } \\
\text { V not } \\
\text { Assumed }\end{array}$ & 175.9 & .000 & 87.73 & 28 & .000 & 193.8 & 2.209 & 189.2 & 198.3 \\
\hline
\end{tabular}

\section{DISCUSSION}

In EFL contexts, reading and the ability to read and comprehend foreign texts is one of the most important goals of the learners. Since development of literacy skills in early childhood are predictors of children's success in reading (Adams, 1990; Donaldson, 1978; Snow et al., 1998; Whitehurst \& Lonigan, 1998), as well as the fact that bottom-up processing is more important than top-down processing at the first stages of learning (Paran, 1996; Birch, 2002; Koda, 2005, as cited in Hinkle, 2006), and because the teaching-learning formula in Iran does not focus on bottom-up processing; this study aimed at investigating the effect of print media use and direct instruction on literacy development in children.

The analysis of the data revealed that subjects in experimental group outperformed those in control group in phonemic awareness, reading fluency, and te xt comprehension. In other words, treatment, i.e. print media use and direct instruction affect reading sub-skills positively. Subjects who received instruction that focuses on phonemic awareness made greater gains in spelling, i.e. phoneme segmentation and phonemic awareness, reading and text comprehension than those subjects who had not received such instruction. As a result, phonemic awareness instruction improves children's ability to read words and help them learn to read. Since phonemic awareness instruction has influence on word reading, it aids reading comprehension and therefore it improves children's reading comprehension. When children improve their rapid and accurate word reading skill, they could shift their focus from the letters of the words to the meaning of what they read.

Students differ in their phonemic awareness, i.e. some need more instruction than others. In addition, students have different learning styles (communicative, authority oriented, concrete, and analytical). Using media in classroom, therefore, would provide opportunities for the students to use information and instruction based on their styles and their need (Brinton as cited in Celce-Murcia, 2001).

These findings contribute to bottom-up processing theory and its importance as a stepping stone to better reading ability (Paran, 1996; Birch, 2002; Koda, 2005, as cited in Hinkle, 2006), and permit a clearer understanding of previous findings about the fact that reading ability can be affected by many factors such as pre-reading skills, i.e. phonemic awareness (National Reading Panel, 2000), and the knowledge of the language of the text (Eskey, 2005).

Although the subjects were familiar with English alphabet at the outset of the study, they were not able to s egment and read simple words in the first sub-test of DIBELS phoneme segmentation test. However, through print media usage, i.e. story books, magazines, and newspapers to teach areas of reading proficiency, the students became able not only to segment and read the words, but also to read and comprehend the text they read. Considering the other side of the coin, the subjects in control group were not able to read and segment the simple words at the end of the study. Their reading 
fluency was very low and since they did not have essential knowledge of the language of the text, they were not able to process L2 reading schemata and texts (Eskey, 2005). Through bringing the outside world into the class room (print media usage), the subjects in experimental group developed their pre-reading skill, they read effortlessly and they learned how to read. As a result, the Matthew effect (Stanovich, 1986) can be seen here.

\section{CONCLUSION}

To sum up, the current study investigated the effect of print media use on children L2 literacy development. The results revealed that use of print media in classroom to teach pre-reading skills and reading skills has a positive effect on reading ability development. In other words, as the learners' knowledge of the language of the text grows, the reading fluency and text comprehension will increase. The development of emergent literacy skills happens in preschool years, hence shows the importance of instruction in these years. Phonological awareness and letter knowledge are the best predictors of later achievement in reading (Adams, 1990; Snow et al., 1998). Oral language is highly correlated with emergent literacy knowledge as well (Justice and Pullen, 2003). In short, successful reading ability relies on mastering a certain level of phonological awareness. Moreover, phonological awareness instruction is helpful for most children, but the degree of explicitness should be changed according to the learner's skills and styles. Teachers can benefit from print media use in clas srooms, therefore, to meet the different needs of their students.

The results show that the students' skills grew in letter naming, phoneme segmentation, reading fluency, and text comprehension. Therefore, the results imply the effect of direct instruction and print media usage on the developing of foreign language reading abilities. Understanding the structure of the text will lead students to read with more understanding. Newspaper, magazine, and story books text structure is predictable and exposes stude nts to multiple input sources. They are concise and well written and can become a model for learners' writing. Print media activities provide situations for learners to practice skills they have learned in years and to work together to develop their social skills as they learn to accept and appreciate differences in others. The print med ia provides situations for students to see the linkage between writing and reading. As a result, print media can be considered as a bridge between school writing and real world writing. And therefore, the results could encourage the teachers to use print media in their classrooms in order to develop students' reading ability.

There are some limitations to the present study. First is that the sample of the present study was limited to EFL learners with Persian as their L1. This limits the scope for generalization of the research findings. Second, the number of the participants was very limited and sex was controlled. Larger samples with mixed genders, hence more representative of the larger population, may yield more conclusive results.

\section{REFERENCES}

[1] Adams, M. (1989). Beginning to read: Thinking and learning about print. Cambridge, MA: MIT Press.

[2] Adams, M. J. (1990). Beginning to read: Thinking and learning about print. Cambridge: MIT Press.

[3] Alderson, J.C. (2000). Assessing Reading. Cambridge: C.U.P.

[4] Baker, S., \& Gersten, R. (1997). Exploratory meta-analysis of instructional practices for English-language learners (Tech Rep. No. 9701). Eugene, OR: Eu gene Research Institute.

[5] Baydar, N., Brooks-Gunn, J., \& Furstenberg, F. F. (1993). Early warning signs of functional literacy: Predictors in childhood and adolescence. Child Development, 64, 815-829.

[6] Blaunstein, P., \& Lyon, G. R. (2006). Why kids can't read: Challenging the status quo in education. Boston: Rowan \& Littlefield.

[7] Celce-Murcia, M. (2001). Teaching En glish as a second or foreign lan guage. United States of America: Heinle \& Heinle.

[8] Chikamatsu, N. (1996). The effects of L1 orthography on L2 word recognition. Studies in Second Language Acquisition, 18, 403-432.

[9] Clay, M. M. (1993). Reading recovery: A guidebook for teachers in training. Portsmouth, NH: Heineman.

[10] Dickinson, D. K., \& Tabors, P. O. (2001). Beginning literacy with language. B altimore: Brookes.

[11] Donaldson, M. (1978). Children's minds. New York: Norton.

[12] Edyburn, D. L. (2002). Born digital: Technology in the life of students starting kindergarten, high school, and college. Special Education Technology Practice, 4(4), 48-59.

[13] Eskey, D. (1988). Holding in the bottom: An interactive approach to the language problems of second language readers. In P. Carrell,J. Devine, \& D. Eskey (Eds.), Interactive approaches to second language reading (pp. 93-100). Cambrid ge: Cambridge University Press.

[14] Eskey, D. (2005). Reading in a second language. In E. Hinkel (Ed.), Handbook of research on second language teaching and learning (pp. 563-580). Mahwah, NJ: Lawrence Erlbaum.

[15] Foorman, B., \& Torgesen, J. K. (2001). Critical elements of classroom and small-group instruction to promote reading success in all children. Learning Disabilities Research and Practice, 27, 641-646.

[16] Francis, D., Shay witz, S., Stuebing, K., Shay witz, B., \& Fletcher, J. (1996). Developmental lag versus deficit models of read ing disability: A longitudinal, individual growth curves analy sis. Journal of Educational Psychology, 88(1), 3-17.

[17] Garcia, G. (2000). B ilingual children's reading. In M. L. Kamil, P. B. Mosenthal, P. D. Pearson, \& R. Barr (Eds.), Handbook of reading research (Vol. III, pp. 813-834). Mahwah, NJ: Erlbaum.

[18] Gersten, R., \& Geva, E. (2003). Teaching reading to early lan guage learners. Educational Leadership, 60(7), 44-47.

[19] Grabe, W. (1991). Current developments in second lan guage reading research. TESOL Quarterly, 25(3), 375-406. 
[20] Good, R. H., \& Kaminski, R. A. (Eds.). (2007). Dynamic Indicators of Basic Early Literacy Skills (6th ed.). Eugene, OR: Institute for the Development of Educational Achievement. Retrieved January 11, 2008 from http://dibels.uoregon.edu/

[21] Goswami, U. (2000). Phonological and lexical processes. In M. L. Kamil, P. B. Mosenthal, P. D. Pearson \& R. Barr (Eds.), Handbook of reading research (Vol. III, pp. 251-267). Mahwah, New Jersey: Lawrence Erlbaum Associates.

[22] Hinkle, E. (2006). Current perspectives on teaching the four skills. TESOL QUARTERLY, 40 (1), 63-94.

[23] Jewitt, C. (2006). Technology, literacy and learning: a multimodal approach. New York: Routledge.

[24] Jonassen, D. H., \& Howland, J. (2003). Learning to solve problems with technology: a constructivist approach. Upper Saddle River, NJ: Merrill Prentice Hall.

[25] Juel, C. (1988). Learning to read and write: A longitudinal study of 54 children from first through fourth grades. Journal of Educational Psychology, 80, 437-447.

[26] Justice, L. M., \& Ezell, H. K. (2001). Written language awareness in preschool children from low-income households: A descriptive analy sis. Communication Disorders Quarterly, 22, 123-134.

[27] Justice, L. M., \& Pullen, P. (2003). Early literacy intervention strategies: A review of promising findings. Topics in Early childhood Special Education, 23, 99-113.

[28] Koda, K. (1999). Development of L2 intraword orthographic sensitivity and decoding skills. Modern Language Journal, 83, 51-64.

[29] Lane, H. B., Pullen, P. C., Hudson, R. F., \& Konold, T. R. (2009). Identifying essential instructional components of literacy tutoring for struggling beginning readers. Literacy Research and Instruction, 48, 277-297.

[30] Lie, A. (1991). Effects of a training program for stimulating skills in word analysis in first-grade children. Reading Research Quarterly, 26 (3), 234-250.

[31] National Reading Panel. (2000). A report of the National Reading Panel: Teaching children to read. Washington, DC: National Institute of Child Health and Human Development.

[32] Richards, J. C. \& Renandya W. A. (2002). Methodology in Language Teaching: An Anthology of Current Practice. United States of America: Cambridge University Press.

[33] Shimron, J., \& Savon, T. (1994). Reading proficiency and orthography: Evidence from Hebrew. Language Learning, 44, 5-27.

[34] Siraj-Blatchford, J., \& Whitebread, D. (2003). Supporting ICT in the early years. Buckingham, England: Open University Press.

[35] Snow, C. E., Burns, M. S., \& Griffin, P. (Eds.). (1998). Preventing reading difficulties in young children. Washington, DC: National Academy Press.

[36] Stanovich, K. (1986). Matthew effects in reading: Some consequences of individual differences in the acquisition of literacy. Reading Research Quarterly, 21(4), 360-407.

[37] Torgesen, J. K. (2004). Preventing early reading failure. American Educator, 28, 6-19.

[38] Torgesen, J. K., \& Burgess, S. R. (1998). Consistency of reading-related phonological processes throughout early childhood: Evidence from longitudinal-correlational and instructional studies. In J. Metsala \& L. Ehri (Eds.), Word recognition in beginning reading. Hillsdale, $\mathrm{NJ}$ : Erlbau m.

[39] Torgesen, J. K., Morgan, S. T., \& Davis, C. (1992). Effects of two types of phonological awareness training on word learning in kinder garten children. Journal of Educational Psychology, 84(3), 364-370.

[40] Vellutino, F. R., \& Scanlon, D. M. (1987). Phonological coding, phonological awareness, and reading ability: Evidence from a longitudinal and experimental study. Merrill-Palmer Quarterly, 33(3), 321-363.

[41] Wagner, R. K., Torgesen, J. K., Rashotte, C. A., Hecht, S. A., Barker, T. A., \& Burgess, S. R. (1997). Changing relations between phonological processing abilities and word-level reading as children develop from beginning to skilled readers: A 5year longitudinal study. Developmental Psychology, 33(3), 468-479.

[42] Whitehurst, G. J., \& Lonigan, C. J. (1998). Child development and emergent literacy. Child Development, 69, 848-872.

Mansoor Tavakoli holds a $\mathrm{PhD}$ in applied linguistics from Isfahan University, Iran. He is an assistant professor and has been involved with teaching TEFL courses for over 15 years at the University of Isfahan. His research interests are in the areas of second language acquisition, second language teaching and assessment. He has published several articles in these respects.

Saeedeh Esmae'li holds an MA in TEFL from Isfahan University, Iran. She has taught English courses in different institutes in Iran. Her main research interests are language teaching and assessment, second language acquisition and language teaching methodology. 